\title{
Ex-post Analysis of Mobile Telecom Mergers: The Case of Austria and The Netherlands
}

\author{
Luca Aguzzoni $^{1}$ • Benno Buehler ${ }^{1}$ - Luca Di Martile ${ }^{1}$. \\ Ron Kemp ${ }^{2,4}$ • Anton Schwarz ${ }^{3}$
}

Published online: 24 November 2017

(C) The Author(s) 2017. This article is an open access publication

\begin{abstract}
Recently there has been an increased attention towards the ex-post evaluation of competition policy enforcement decisions and in particular merger decisions. In this paper we study the effects of two mobile telecommunication mergers on prices. We apply a standard difference-in-differences approach which is widely used in the literature on ex-post evaluation of mergers. For the Austrian T-Mobile/tele.ring merger, we conclude that after the acquisition (for which remedies were imposed) prices in Austria did not increase relative to the considered control countries. For the Dutch T-Mobile/Orange merger, we observe an increase in the mobile tariff prices in the Netherlands in the analysed period, relative to the control countries. We cannot firmly establish whether this price increase was exclusively caused by the T-Mobile/Orange merger or in part by possible price effects brought about by the KPN/Telfort merger consummated twoyears earlier in the Netherlands. However, we believe that such price increase could be linked to the structural changes brought by both KPN/Telfort and T-Mobile/Orange mergers together.
\end{abstract}

\footnotetext{
This paper is based on the report "Ex-post evaluation analysis of two mobile telecom mergers: T-Mobile/tele.ring in Austria and T-Mobile/Orange in the Netherlands" available at https://ec.europa.eu/ competition/publications/reports/kd0215836enn.pdf. The views expressed in this article are personal and do not necessarily represent those of DG Competition, the European Commission, ACM, RTR or the Telekom-Control-Kommission.

$\bowtie$ Ron Kemp

ron.kemp@acm.nl

1 European Commission, DG Competition, Bruxelles, Belgium

2 Netherlands Authority for Consumers and Markets, The Hague, The Netherlands

3 Austrian Regulatory Authority for Broadcasting and Telecommunications, Wien, Austria

4 Erasmus University Rotterdam, Rotterdam, The Netherlands
} 
Keywords Competition law enforcement - Merger control · Ex-post studies . Telecommunications

JEL Classification D49 · K29 · L50 · L96

\section{Introduction}

Companies use mergers to combine forces in order to expand markets, develop new products more efficiently or reduce production or distribution costs. However, some mergers may reduce competition as well which may harm consumers through higher prices, reduced choice or less innovation and quality. The objective of merger control is to ensure that notified mergers are only cleared if they are not expected to entail significant anticompetitive effects on parameters like price, quality, innovation and variety. While the merger control is usually based upon expectations and hypotheses, ex-post evaluation can shed light on the actual procompetitive or anticompetitive effects of consummated mergers.

Recently, increased attention is being paid to ex-post evaluation of competition policy enforcement decisions, and in particular merger decisions. In the United States, there is already an established and voluminous body of studies that covers several industries and several types of decisions (Kwoka 2013).

In this paper, we empirically examine the effects on retail prices of two mergers in the mobile telecommunication industry:

- T-Mobile-tele.ring merger in Austria, approved with remedies ${ }^{1}$ in April $2006 .{ }^{2}$

- T-Mobile-Orange merger in the Netherlands, approved without remedies in August $2007 .^{3}$

This paper hence contributes to a limited, but growing, number of ex-post assessments in Europe (Mariuzzo et al. 2016) and aims at improving our understanding of consummated mergers.

The mobile telecom industry is an industry of significant interest for merger control, as the European mobile telecom sector has witnessed several recent mergers between independent mobile network operators in a number of different national markets. Mergers in that industry also tend to have long-lasting effects due to very high entry barriers because of the need to acquire very costly spectrum and to roll out a mobile network. The mobile telecom industry also presents a number of interesting specificities (complex tariff offers, non-linear prices) that this study tries to address and that might also be relevant to other industries.

\footnotetext{
1 Remedies are modifications to the merger plans that would preserve the competition condition absent the merger. They can take the form of structural remedies (e.g. divestment of certain activities or a division) or behavioural remedies (e.g. price regulation or access to certain facilities).

2 The Commission's case reference is M.3916. Further information is available under http://ec.europa.eu/ competition/elojade/isef/case_details.cfm?proc_code=2_M_3916.

3 The Commission's case reference is M.4748. Further information is available under http://ec.europa.eu/ competition/elojade/isef/case_details.cfm?proc_code=2_M_4748.
} 
Mainly due to issues of data availability, this study is limited to the effects of the mentioned mergers on retail prices. We are aware, however, that a merger may also affect other market outcomes such as investments and quality. ${ }^{4}$

Insights of retrospective merger evaluations can contribute to improving the enforcement practice of competition authorities in various ways. Retrospective merger analysis allows testing the merits of arguments commonly brought forward in past cases. Ex-post evaluation can also help competition authorities to calibrate the merger policy by identifying potential systematic biases in merger decisions. For example, in a recent survey, Kwoka (2013) finds that mergers which are conditionally cleared in the US often still had significant anti-competitive effects.

This study applies reduced-form econometric methods typically used in the socalled treatment evaluation literature, which are commonly applied also to the ex-post assessment of competition policy. Effectively, we compare, both before and after the merger, the price development of the country in which the respective analysed merger took place ("affected country") with a number of countries in which no structural change took place over the same period ("control countries"). This permits to estimate the price development that would have been observed in the country of interest absent the merger and to identify the merger effect. Specifically, we apply a difference-indifferences (DiD) approach which is widely used in the policy evaluation literature and for ex-post evaluation of mergers. We also test whether our identifying assumption of "common trends" in the studied countries is met pre-merger. As in many case studies, we observe only a single affected country, and overall we have a small sample (in statistical terms) of control countries. We address this challenge by applying recent approaches to improve the estimation of standard errors.

The remainder of the paper is organized as follows. In the next section, we give a short introduction of the context of this study, merger control, the mobile telecommunication sector and the selected cases. Section 3 describes the data and the empirical approach. Section 4 presents the results. Section 5 concludes.

\section{Study Context}

\subsection{Merger Control}

Mergers are an extremely common phenomenon in market economies. For instance, since 2000 more than 5000 cases were notified to the European Commission (EC) and many more were notified to national competitions authorities. If merging parties reach a certain turnover threshold they have to notify their merger (either to national authorities or to the EC). In a typical EC merger case, after notification, the EC assesses whether the merger would significantly reduce competition to the detriment of consumers. The EC's investigation of the merger effects is divided in two phases, a preliminary investigation (Phase 1) and in-depth investigation (Phase 2) that may follow. In Phase

\footnotetext{
${ }^{4}$ Mobile internet was in its early stages of development in the period considered in this study, and therefore network coverage and network performance for mobile data is not particularly relevant. Mobile network coverage for voice and SMS services would have been an important metric to study. However, network coverage for voice and SMS was generally high for all the operators considered and there is was no significant variation over time in the period under analysis.
} 
1 most mergers are cleared, either unconditionally or subject to remedies. Mergers that raise concerns are further investigated in Phase 2. In this phase, the merger may be unconditionally cleared, cleared subject to remedies or prohibited. Of the more than 5000 EC merger cases notified between 2000 and 2016, only about 170 reached Phase 2 of the proceeding.

If two competitors merge the most direct effect is the loss of competition between the merging firms, which normally triggers the incentive for the merging parties to raise prices post-merger. Moreover, to the extent prices are strategic complements, unilateral price increases by the merging parties may be followed by price increases by the non-merging firms even without coordination (i.e. collusion) among market players (Ivaldi et al. 2003).

A merger can also entail (consumer) welfare-enhancing effects. This may be the case if the merger leads to increased efficiency and lower costs (or better quality), and the benefits are passed through to consumers.

The total effect of a merger depends on the magnitude of anti-competitive effects and efficiency gains. If the anti-competitive effects are more pronounced than the efficiency gains, the outcome for consumers deteriorates. This will often lead to higher prices, compared to the scenario without the merger. If the merging firms can realise sufficient efficiency gains and the remaining competition is strong enough, a merger may improve the outcome for consumers.

\subsection{Mergers in the Mobile Telecommunication Sector}

Table 1 lists the EC merger cases in the mobile telecommunication sector between 2006 and 2016. ${ }^{5}$ In eight of the ten cases, there was a concentration from four to three Mobile Network Operators (MNOs). ${ }^{6}$ Two merger cases were unconditionally cleared, six were cleared subject to remedies, one was prohibited, and one was withdrawn. From 2012 onwards all merger cases notified to the EC reduced the number of competitors in the market from four to three, and raised competition concerns such that remedies where required or the concentration was prohibited (and in one case was withdrawn).

The mobile telecommunication market is an important market with a lot of publicly available data, but empirical studies, like ours, on the effects of mergers in the telecommunications industry have been limited so far. To our knowledge, these include studies by Csorba and Pápai (2013), Nitsche and Affeldt (2014), Genakos et al. (2015) and Frontier Economics (2015). While these studies use data on entries of new MNOs and mergers in several countries to identify the effect that a change in market structure brings to the mobile telecom industry in general (e.g. new entrants, five-to-four mergers, four-to-three mergers, etc.), we analyse two mergers in two different countries separately and independently.

\footnotetext{
5 This table exclusively contains mobile telecom mergers that were assessed by the EC. However, in line with the applicable rules on jurisdiction, mergers that involve parties which generate a large part of their revenues in a given member state are typically dealt with by the national competition authorities, as was the case for the KPN/Telfort merger in the Netherlands also discussed in this report.

6 MNOs need the tangible assets (i.e. hardware for a radio access network), and the intangible assets (i.e. the license to use certain radio frequencies for mobile telecommunication, called spectrum).
} 


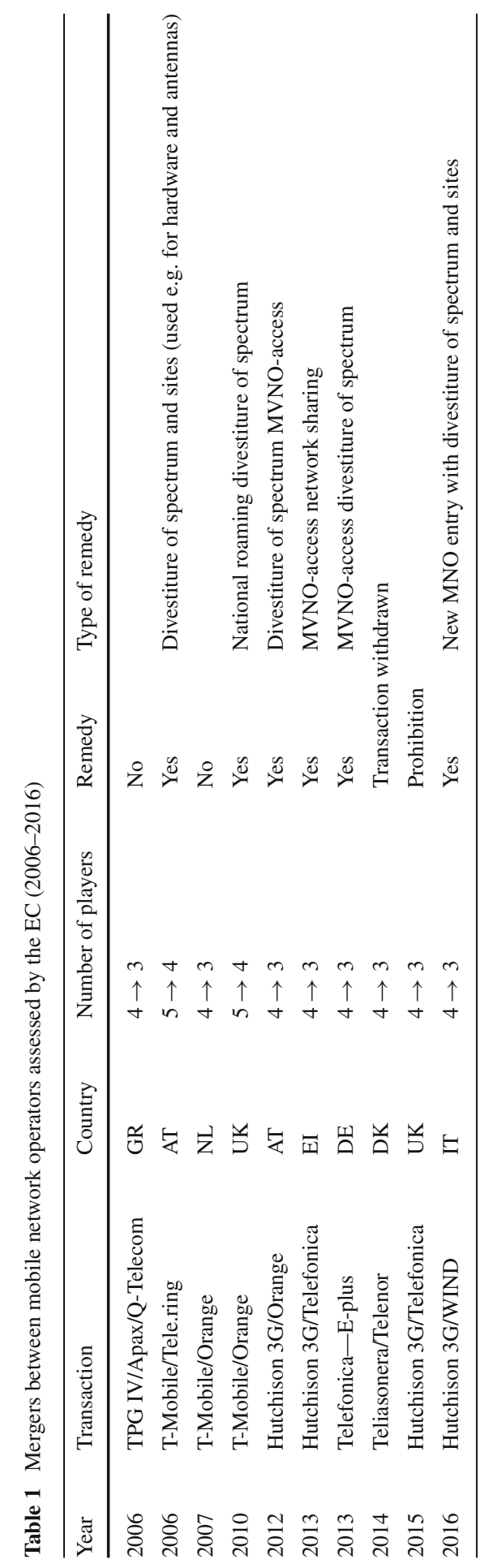


The T-Mobile/tele.ring merger in Austria was cleared subject to structural remedies (i.e. divestment of assets) in April 2006 after an in-depth investigation by the EC. At the time of the merger there were five mobile network operators (MNOs) active on the Austrian market: Mobilkom Austria (the incumbent with a market share of around 40\%); T-Mobile (24\%); Orange (20\%); tele.ring (12\%) and Hutchison 3G (or $\mathrm{H} 3 \mathrm{G}$, with a market share of $3 \%$, having just entered the market in 2003). The EC's investigation concluded that tele.ring was the most aggressive player in the mobile market and exerted competitive pressure especially on T-Mobile and Mobilkom. The proposed transaction raised serious competition concerns and was only approved after T-Mobile offered a package of remedies which consisted of the transfer of parts of tele.ring's spectrum and mobile telecommunication sites to H3G and Orange.

The T-Mobile/Orange merger in the Netherlands was cleared without remedies by the EC in August 2007. Prior to the T-Mobile/Orange merger, KPN was the market leader with a retail market share in terms of subscribers of roughly $39 \%$. Other MNOs active in the mobile telecommunications market were Vodafone with $21 \%$ subscriber market share, T-Mobile (14\% subscriber market share), and Orange (12\%). With the acquisition of Orange, T-Mobile became the second largest MNO in the Netherlands with a market share exceeding $25 \%$. Mobile Virtual Network Operators (MVNO) ${ }^{7}$ have a combined subscriber market share of around $15 \%$.

Compared to many other mobile telecommunication markets in Europe, there was a fast-growing presence of the MVNO segment in the Dutch retail mobile telecom market. This is reflected in the EC's clearance decision of the T-Mobile/Orange merger that points to the strong presence of the MVNOs as one of the factors countervailing the possible loss of competition from the reduction in the number of MNOs in the Netherlands' mobile telecom market.

One important specificity of the Dutch case study is that the T-Mobile/Orange merger was preceded by another merger between KPN and the by then fifth-largest MNO Telfort, which was unconditionally cleared in August 2005 by the Dutch competition authority.

\section{Data and Empirical Approach}

\subsection{Data}

A specific challenge of estimating merger effects in the mobile telecom industry relates to the fact that consumers generally purchase a bundle of mobile telecommunications services. Subscribers may inter alia place mobile calls, send text messages (SMS) and may also use mobile data services. A mobile tariff is usually characterized by the amount of mobile services (voice calls, SMS, mobile data) included in the monthly fee, the unit prices for the different "out of bundle" mobile services, as well as further fees such as set-up fees and connection fees. The total expenditure of a subscriber for mobile

\footnotetext{
7 Compared to MNOs, MVNOs do not own the essential facilities to run a mobile network. In contrast, MVNOs lease the access to the network of one of the MNOs. MNOs normally are not obliged to grant access to their network, access is usually granted on commercial basis and it is not regulated.
} 
services is then determined based on the usage and on the chosen tariff plan. Given these specificities, one of the challenges in analyzing the mobile telecommunications market is to derive a one-dimensional price index to measure the "price level". In this study, we derive the price index by measuring the monthly expenditure of representative consumers for which we collected a representative usage pattern. The effect of the merger is then estimated on this monthly expenditure. We refer to this measure as "price". For the computation of the price, we focus on active tariffs that are offered by MNOs at a given moment in time and exclude tariffs that cannot be selected by new customers any more. ${ }^{8}$ We consider the former as the relevant tariffs because competition in the telecom market focuses on the tariffs available at any given point in time, and prices are mostly adjusted by introducing new tariffs, rather than changing the price of existing or legacy tariffs. Therefore, possible price effects of a merger can be observed more clearly when focusing on offered tariffs. This approach is also followed by other econometric studies of the mobile telecom sector such as Genakos et al. (2015) and Csorbaet al. (2015).

Another characteristic of the mobile telecom industry is price discrimination through nonlinear tariff plans. That is, operators typically offer quantity discounts by means of tariffs with more included minutes, SMS and mobile data and a higher absolute price but a lower unit price for the different components than bundles with fewer included units. Consumers with different usage characteristics self-select into their preferred tariff plan. For this reason, we estimate the merger effects separately for three representative consumer types by usage patterns (i.e. consumers with low, mid and high usage).

We collected detailed country level tariff data for the periods both before and after the merger. We use three different sources for tariff data. A first dataset covering the tariffs of the largest two operators in fourteen European countries (AT, BE, CH, CZ, DE, DK, FI, FR, HU, IT, NL, SE, PT, UK) on a quarterly basis between 2004 and 2010 was obtained from the data provider Teligen. For both the Netherlands and Austria, a richer set of data was available. In our analysis we combined those datasets with the Teligen data including in the latter only the set of countries representing the control group..$^{9}{ }^{10}$ In this respect, we consider the prices of the largest two operators as a valid proxy for the development of the market price in the control group of countries. For the Netherlands, the richer set of data was obtained from the provider Telecompaper that covers tariffs of all operators in the Netherlands on a quarterly basis between 2004 and 2010. For Austria, the richer set of data was obtained from the Austrian chamber of labour (Arbeiterkammer), and covers the tariffs of all Austrian operators on a quarterly basis between 2004 and 2010 .

The final datasets cover in each quarter the full range of retail tariff plans available to new customers and contain all the tariff characteristics required to calculate the price

\footnotetext{
8 Tariffs often have minimum contract duration and a significant number of customers are typically subscribed to tariffs that are not offered to new customers any more.

${ }^{9}$ However, using the Teligen data with only the two largest operators for Austria and the Netherlands would not materially change the results.

10 Austria and the Netherlands are not included in the control group of one another.
} 
for each tariff given a certain usage pattern (number of voice minutes and SMS). ${ }^{11}$ All datasets cover pre-paid as well as post-paid tariffs. MNOs often offer very low and subsidized handset prices and expect to recoup those initial handset subsidies via the monthly payments of the subscribers. Handset subsidies, if part of the tariff, are not separately identified in the available datasets. This may have an impact on the price effects that we estimate, especially if handset subsidies are also affected by the mergers we study. To control for this possibility, we estimate a robustness test of our model including only pre-paid tariffs, as those tariffs are generally less affected by handset subsidies.

To approximate the usage of the representative consumer, we collected the average mobile telecommunications usage in each country, obtained from publicly available sources (e.g. websites of the relevant national regulatory authorities). ${ }^{12}$ We use country-specific consumption bundles in order to better reflect the countries' specificities and the significant differences across consumption preferences and resulting price patterns. The average voice and SMS usage for the fourteen countries is depicted in Table 2.

The countries' average usage baskets (minutes and SMS) was kept constant over the period considered in the analysis to prevent changes in the consumption pattern from influencing the tariffs' price series. This allows us to clearly separate price effects (changes in the tariffs offered) from quantity effects (changes in usage). We therefore consider this approach as more appropriate than an approach where usage changes over time. For the analysis of the Austrian merger, we use for each country in the analysis the 2006 consumption levels while for the Dutch merger we use 2007 levels (i.e. the years of the respective mergers under analysis).

To analyse the effects in different market segments and also to cover a larger range of tariffs, we construct a High and a Low usage basket based on the average usage of Table 2. The factors applied to rescale the average (Mid) usage basket are taken from the OECD's study on mobile tariffs (OECD 2006) and are depicted in Table 3.

\footnotetext{
11 Our calculation follows a similar methodology as OECD (2006). The included tariff characteristics are: activation charge/connection fee (spread over 24 months); monthly fixed fee; minimum monthly fee; number of included minutes/SMS and; price per out of bundle minute/SMS — by target network and peak/off-peak time. Mobile data services were not relevant in the studied period.

The assumed average call duration is $2 \mathrm{~min}$. The off-net calls are split equally among the other MNOs active in the country. The shares of peak and off-peak (i.e. evenings and weekends) calls are $50 \%$. The peak/off-peak and on-net/off-net split does not materially affect the prices as for most tariffs, the voice prices do not depend on time (peak/off-peak) and destination network (on-net/off-net).

To improve the comparison across countries, we applied the following adjustments: deducting applicable value added taxes from the tariff price series because in some countries the VAT changed during the period of the analysis; incorporating inflation by computing real prices using the Harmonised Indices of Consumer Prices (HIPC); converting the price from local currencies into EURO, for non-Euro countries (Czech Republic, Denmark, Hungary, Sweden and the UK) based on a constant nominal average exchange rate over the years 2004-2009 in order to limit the impact that fluctuations of the exchange rate may have on the countries' price series.

12 The average usage also reflects the usage of customers on legacy tariffs. Given that there is a trend of falling prices, the average usage per subscriber on available tariffs (as opposed to legacy tariffs) may be somewhat higher than that of customers on legacy tariffs. However, we account for this possibility by also estimating the price effects for the high usage basket, which significantly exceeds the average usage.
} 


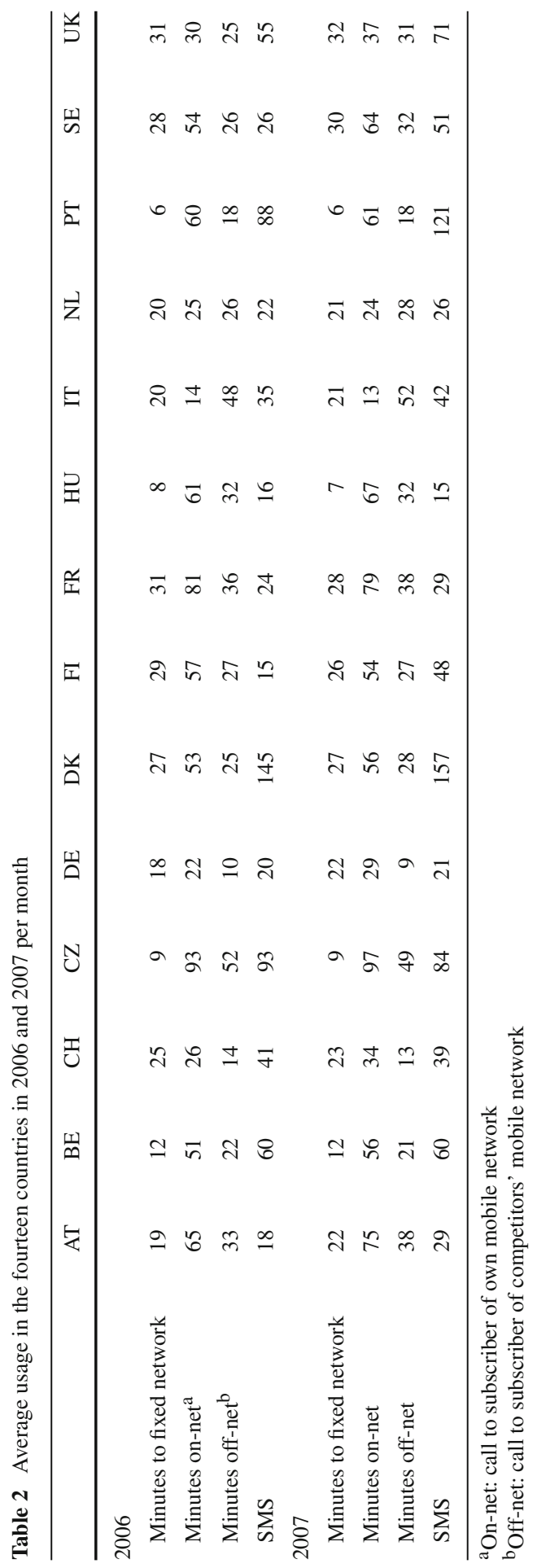


Table 3 Factors for Low and High usage basket based on OECD Baskets

\begin{tabular}{lll}
\hline Basket & Minutes factor & SMS factor \\
\hline Low & 0.46 & 0.66 \\
Mid & 1 & 1 \\
High & 2.15 & 1.1 \\
\hline
\end{tabular}

We intend to capture the evolution of the prices of those tariffs that are likely to be purchased by an average consumer whose consumption pattern resembles the usage baskets described above. To this end, for each usage basket we include only the prices of the four cheapest tariffs per operator in our estimation. We could have considered a smaller number of tariffs (i.e. the cheapest tariff available given the consumption pattern). However, we believe that including the four cheapest tariffs has some advantages. First, it can reflect a higher degree of heterogeneity across the users for each usage basket. Second, users may not know their exact usage in advance and may not choose the tariff which is the cheapest from an ex-post perspective. Third, this approach averages out smaller measurement errors of tariffs or outliers due to specific tariff plans targeted to specific customer segments (e.g. a family tariff plan). Nevertheless, as a robustness check, we also focus on the two cheapest tariffs only.

Table 4 shows summary statistics for Austria, the Netherlands and the respective control groups separately for the pre-merger and the post-merger period. In the period considered, prices dropped for Austria and the Netherlands as well as for the control group. This holds true for all three baskets. Mobile termination rates (MTRs), ${ }^{13}$ an important cost driver, were also reduced within this time frame.

Figure 1 shows the average prices of the four cheapest tariffs of all MNOs in the dataset for the Mid basket in the affected countries (Austria and the Netherlands) and in the twelve countries which potentially serve as control group. All countries experience a downward trend in the mobile telecom price for the Mid consumption basket. However, some countries experienced a faster reduction in prices than others.

In order to control for market developments not associated with the mergers, we included the control variables mobile termination rates and GDP growth. Since MTRs are due for each call to other mobile networks (off-net), they can be considered as a proxy for marginal costs of voice calls. The growth of gross domestic product per capita (GDP) is included as a proxy for changes in demand conditions. In order to control for further unobservable factors affecting the price series, we include in the analysis quarterly and country-MNO fixed effects. ${ }^{14}$

\footnotetext{
13 Mobile termination rates are fees paid by MNOs to competitors for calls which terminate on the latters' networks. The rationale of the MTRs is to compensate the operators for the network costs associated with incoming calls.

14 The country-MNO fixed effects allows for the possibility that the pricing of the same operator is affected by different fixed effects in different countries.
} 
Table 4 Descriptive statistics Austria versus control group

\begin{tabular}{|c|c|c|c|c|c|c|}
\hline & \multicolumn{3}{|c|}{ Austria } & \multicolumn{3}{|c|}{ Control countries } \\
\hline & $\mathrm{N}$ & Mean & $\mathrm{SD}$ & $\mathrm{N}$ & Mean & $\mathrm{SD}$ \\
\hline \multicolumn{7}{|l|}{ Panel a: Austria } \\
\hline \multicolumn{7}{|l|}{ Pre-merger } \\
\hline Low Price Basket & 160 & 18.08 & 5.31 & 703 & 16.09 & 6.02 \\
\hline Mid Price Basket & 160 & 26.26 & 5.59 & 703 & 26.50 & 8.24 \\
\hline High Price Basket & 160 & 39.21 & 8.43 & 703 & 44.98 & 13.66 \\
\hline MTR & 160 & 0.13 & 0.01 & 703 & 0.14 & 0.04 \\
\hline GDP growth & 160 & 0.01 & 0.00 & 703 & 0.01 & 0.01 \\
\hline \multicolumn{7}{|l|}{ Post-merger } \\
\hline Low Price Basket & 160 & 10.63 & 4.42 & 704 & 12.27 & 5.57 \\
\hline Mid Price Basket & 160 & 16.43 & 5.35 & 704 & 19.44 & 7.75 \\
\hline High Price Basket & 160 & 25.24 & 7.64 & 704 & 32.38 & 12.65 \\
\hline MTR & 160 & 0.08 & 0.01 & 704 & 0.09 & 0.02 \\
\hline \multirow[t]{3}{*}{ GDP growth } & 160 & 0.01 & 0.00 & 704 & 0.00 & 0.01 \\
\hline & \multicolumn{3}{|c|}{ Netherlands } & \multicolumn{3}{|c|}{ Control countries } \\
\hline & $\mathrm{N}$ & Mean & $\mathrm{SD}$ & $\mathrm{N}$ & Mean & $\mathrm{SD}$ \\
\hline \multicolumn{7}{|c|}{ Panel b: the Netherlands } \\
\hline \multicolumn{7}{|l|}{ Pre-merger } \\
\hline Low price basket & 64 & 13.60 & 2.64 & 384 & 13.15 & 5.15 \\
\hline Mid price basket & 64 & 20.86 & 4.00 & 384 & 21.51 & 7.47 \\
\hline High price basket & 64 & 29.83 & 3.91 & 384 & 35.92 & 12.35 \\
\hline MTR & 64 & 0.11 & 0.00 & 384 & 0.10 & 0.02 \\
\hline GDP growth & 64 & 0.01 & 0.01 & 384 & 0.01 & 0.01 \\
\hline \multicolumn{7}{|l|}{ Post-merger } \\
\hline Low price basket & 104 & 12.98 & 2.96 & 766 & 11.95 & 5.77 \\
\hline Mid price basket & 104 & 20.05 & 3.94 & 766 & 18.37 & 7.17 \\
\hline High price basket & 104 & 28.23 & 3.24 & 766 & 29.94 & 11.56 \\
\hline MTR & 104 & 0.09 & 0.01 & 766 & 0.08 & 0.02 \\
\hline GDP growth & 104 & 0.00 & 0.01 & 766 & -0.01 & 0.01 \\
\hline
\end{tabular}

\subsection{Empirical Approach}

In this study, we applied the difference-in-differences approach. This approach, which goes back to Ashenfelter (1978) and Ashenfelter and Card (1985), has been widely applied in the economic literature on program evaluation for the estimation of treatment effects (see for example the review by Imbens and Wooldridge 2009). While this approach has traditionally been applied in labour and development economics, in more recent years it found application also in industrial economics, and in particular for the ex-post evaluation of mergers (see for example Focarelli and Panetta 2003; 


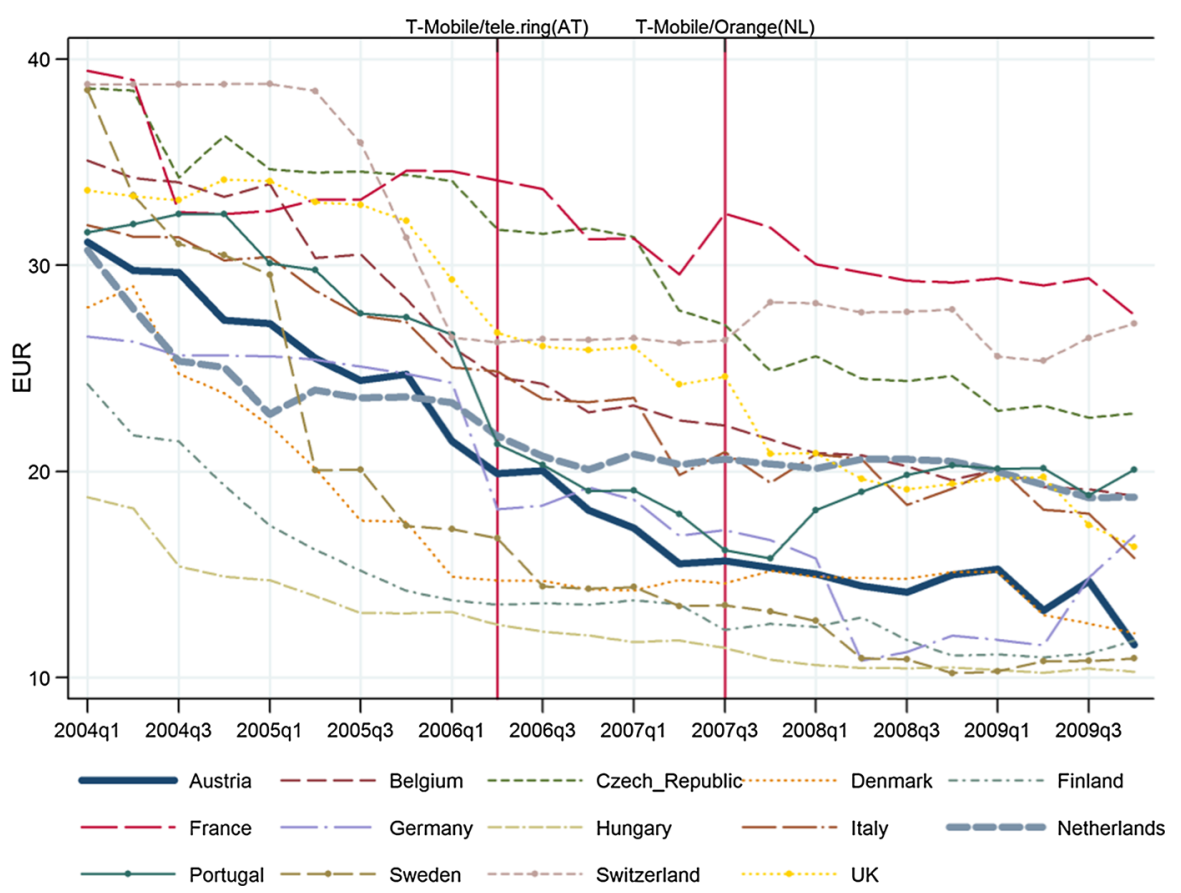

Fig. 1 Countries' price series from 2004 to 2009 (Mid basket)

Ashenfelter and Hosken 2008; Aguzzoni et al. 2011; Choné and Linnemer 2012; Ashenfelter et al. 2013).

In its simplest application, the DiD approach is based on the assumption that the price change over time observed in the control group approximates the price change that would have occurred in Austria and the Netherlands (treated countries) absent the respective mergers. The underlying rationale of this approach is that unobserved effects, like technological developments, have a similar impact both on the control group and on the treatment group. The DiD approach can therefore be applied if the control group satisfies two requirements: first, it is affected by similar unobserved factors as the treated country ("common trends") and second, it is not affected by the studied merger ("no spillover effects").

The merger effect is identified by comparing the average (across group) differences in prices before and after the merger. We estimate for each usage level (Low, Mid and High) the following fixed effects model at the tariff level:

$$
\begin{aligned}
\ln \left(p_{j, i, t, k}\right)= & \gamma_{\text {short }} D_{i, t}^{\text {short }}+\gamma_{\text {medium }} D_{i, t}^{\text {medium }}+\delta_{1} G D P \text { growt } h_{i, t}+\delta_{2} \ln \left(M T R_{i, t}\right) \\
& +\tau_{t}+c_{i, k}+\varepsilon_{j, i, t, k}
\end{aligned}
$$

where $\ln \left(p_{j, i, t, k}\right)$ is the natural logarithm of the real price of tariff $\mathrm{j}$ in country $\mathrm{i}$ at quarter $\mathrm{t}$ offered by MNO $\mathrm{k}, \tau_{t}$ is a time fixed effect for quarter $t, c_{i, k}$ is a fixed effect for country $i$ and MNO $k, D_{i, t}^{\text {short }}$ and $D_{i, t}^{\text {medium }}$ are dummies which take the value 1 for all tariffs in the treated countries (i.e. Austria or the Netherlands) in the first and 
second year after the merger, respectively, and $\varepsilon_{j, i, t, k}$ is an idiosyncratic error term. ${ }^{15}$ Our analysis covers up to eight quarters before and eight quarters after the merger, and we exclude the quarter in which the merger took place. The coefficients of interest are $\gamma_{\text {short }}$ and $\gamma_{\text {medium }}$, which can be interpreted as the average merger effect in the first and second years, respectively, following the merger.

Difference-in-differences estimators are unbiased if the average outcomes of the treated and control groups would follow the same parallel trend over time. We test whether the pre-merger trend of the affected countries is similar to the average trend of the control countries. A similar pre-merger trend may thus suggest that the estimated price effects are reliable (Angrist and Pischke 2008).

We carry out a formal test of the common trend hypothesis. To perform this test we first estimate the deviation of the treated country's price from the average price of the control countries in each quarter. Then, the test assesses whether the deviations of the treated country's price in the pre-merger period follow a different trend than the average price of the control countries. ${ }^{16}$

When the test fails, country specific linear trends can be included in the DiD model. Under this model specification the identification of the effect relies on the assumption that absent the merger the (ln of the) price in the treated country would have followed the same pre-existing (linear) trend that characterized the pre-merger period (after controlling for the other time varying explanatory variables and for the common time effect). So one assumes that the diverging trends will continue in the post-intervention periods between the treatment and control groups.

In the DiD specification with country-specific trends we follow an approach similar to Wolfers (2006). Formally, we estimate the following specification ("Trend specification"):

$$
\begin{aligned}
\ln \left(p_{j, i, t, k}\right)= & \gamma_{t} D_{i, t}+\partial_{i} t+\delta_{1} G D P \text { growt }_{i, t}+\delta_{2} \ln \left(M T R_{i, t}\right)+\tau_{t} \\
& +c_{i, k}+\varepsilon_{j, i, t, k}
\end{aligned}
$$

here, $\partial_{i} t$ represents the country-specific linear trends. We estimate the effect of the merger using the dummies $D_{i, t}$ which take the value 1 for country $i$ and each quarter $t$ after the merger. Hence, in our analyses there are eight dummies. The coefficients $\gamma_{t}$ capture for each quarter the estimated effect of the merger relative to the counterfactual. We then compute the average effect of the merger in the short term (first year) and in the medium term (second year) by taking the average of, respectively, the estimated coefficients of the first four dummies and the last four dummies.

\footnotetext{
15 The estimated coefficients $\gamma_{\text {short }}$ and.$\gamma_{\text {medium }}$ therefore need to be interpreted as the total merger effect in the first and second year, respectively.

16 Formally, we substitute the short-term and medium-term effect dummies in equation (1) with one dummy variable for each quarter that assumes the value of 1 only for the treated country in the relevant quarter. We then compute the slope of a linear trend of the coefficients of these dummies in the pre-merger period and test whether the estimated slope is statistically different from zero using the lincom command in Stata. Our test is similar to the one proposed by Ashenfelter et al. (2013) and to the one discussed by Angrist and Pischke (2008). This test is "passed" when we are not able to reject the null-hypothesis. This however only provides some indication that a common trend may exist pre-merger, in particular because there are only a few pre-merger observations.
} 
However, assuming that diverging trends will continue in the post-intervention periods may not be appropriate, as often trends converge in the long run. In that case, allowing for (linear) country specific trends may even result in more biased estimates than the standard DiD estimator (see O'Neill et al. 2016). Testing the common trend hypothesis and including country specific trends is also sensitive to the number of pre-treatment periods, with results improving in the number of pre-treatment periods. As we only have four to eight pre-merger observations, testing the common trend hypothesis or including a country specific trend can be problematic. Which of the two assumptions (common trend or country specific trend) is more appropriate depends on the specific context but is generally difficult to assess as the merger affects the price development post-merger. Given that both the graphical and statistical analyses show that, in some instances, the common trend assumption is not met pre-merger we present and discuss the results of both specifications. However, also the results of the specification with country specific trends need to be interpreted with caution. ${ }^{17}$

Bertrand et al. (2004) showed that not taking into account existing autocorrelation can lead to underestimated standard errors and therefore the erroneous finding of statistically significant results. Therefore, we account for autocorrelation and heteroscedasticity in the residuals by using a cluster-robust estimator with clustering at the country level. This allows the error terms to be correlated within a country and over time, but not across countries. However, the small sample of available countries (and, therefore, clusters) likely still results in a downward bias in the standard errors, and, in turn, somewhat spuriously increases the statistical significance of the merger effects estimated by the models (Wooldridge 2003).

One way to correct for this bias is to increase the number of clusters by, for example, clustering at MNO-country level. This, however, would assume that the error terms are not correlated across the MNOs of the same country, which we believe is an unreasonable assumption. Another way suggested by the literature to correct for the bias of low number of clusters is to compute standard errors using the wild bootstrap method introduced by Cameron et al. (2008). However, the findings of the wild bootstrap tend to underestimate the significance level of the estimates in case of a strong imbalance in the number of treated units relative to the number of control units, and particularly in case of only one treated unit and few control units, as in our setting (see Brewer et al. 2013; MacKinnon and Webb 2014). This suggests that the true significance level is likely to be somewhere in between the cluster-robust and the wild bootstrap corrections. $^{18}$

\footnotetext{
17 As an illustration, consider the price series for the High basket in the Netherlands shown in Fig. 2. If one estimates a linear trend for the control group on the four pre-merger observations and extrapolates it to the post-merger period, the price becomes almost the same as the price for the Mid basket. In this case, the group specific trend may overcompensate the difference. Testing a non linear relation becomes difficult as we only have four pre-merger observations.

18 Indeed, based on the wild bootstrap method we found $p$ values in excess of 0.1 and much higher than those computed with clustered standard errors. In the following tables, we report the significance of our point estimates based on cluster-robust standard errors, as this is a standard approach which is commonly used in the applied literature.
} 
The econometric specifications in the Netherlands have to be adapted to a number of specificities of the T-Mobile/Orange merger.

First, we cannot exclude that some effects linked to the T-Mobile/Orange merger may have already materialized before the merger was cleared in August 2007. By February 2007 it became public knowledge that France Telecom, which owned Orange Netherlands, was considering the sale of its Dutch subsidiary. Also in February, it was reported that Orange Netherlands had attracted interest from several potential bidders, among which T-Mobile and Vodafone were mentioned. In May 2007, Deutsche Telekom, the mother company of T-Mobile, was reported to have effectively agreed to acquire Orange Netherlands. The MNOs in the Netherlands may have already anticipated the merger in Q2/2007. It is conceivable that once a deal is expected to be struck, this may already affect the pricing of the market participants, even if the merger is not yet formally cleared or closed. For these reasons, we took a conservative approach and excluded from the analysis the two periods Q2/2007 and Q3/2007 in our specification.

Second, the T-Mobile/Orange merger took place roughly two years after the KPN/Telfort merger, which was cleared in August 2005. The KPN/Telfort merger may have affected in particular the pre-merger trend of the T-Mobile/Orange merger. Indeed, we observe that there was a divergence in the trend in the Netherlands and the trend of the control countries in particular in the two quarters following the KPN/Telfort merger. This led us to restrict the pre-merger period when assessing the T-Mobile/Orange merger to four quarters, from Q2/2006 to Q1/2007, while we kept the length of the post-merger period to eight quarters, from Q4/2007 to Q3/2009. The shorter pre-merger period, however, may affect the precision of our estimates, as we have a lower number of observations to disentangle the effect of the merger from the impact of other explanatory variables.

Third, the competitor KPN used a multi-brand strategy (that is, it offered tariffs under several brand names) throughout the analysed period. After the KPN/Telfort merger, KPN kept the Telfort brand in the market, positioning Telfort as a relatively cheaper brand. We cannot include these second brands in our analysis as second brands were not included in the Teligen dataset (which is used for the control countries) until 2006 and the timing as of when sub-brands were included in the Teligen dataset differs across countries. Therefore, second brands (including the Telfort brand of KPN) were excluded from the analysis.

\section{Results}

Figure 2 compares the evolution of the average of the mobile prices of the four cheapest tariffs of each of the MNOs in Austria (Panel a) and the Netherlands (Panel b) and the average mobile price in all the control countries for the three baskets in the period from Q2/2004 to Q2/2008 and Q1/2005 to Q3/2009 respectively. The vertical line in Panel a indicates the quarter of the T-Mobile/tele.ring merger in Q2/2006 and the two vertical lines in Panel b indicate the quarters of the two mergers in the Netherlands' mobile telecom market during the period considered: the KPN/Telfort merger in Q3/2005, and the T-Mobile/Orange in Q3/2007. 


\section{Panel a: Austria}

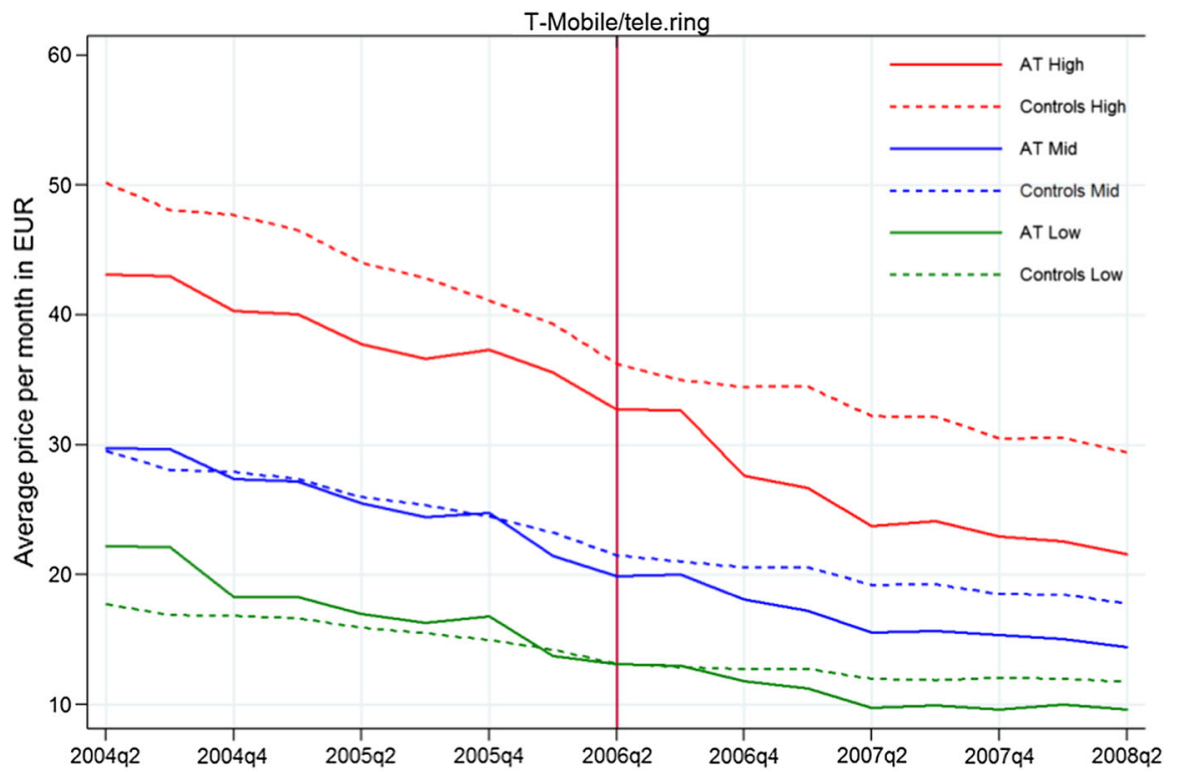

\section{Panel b: Netherlands}

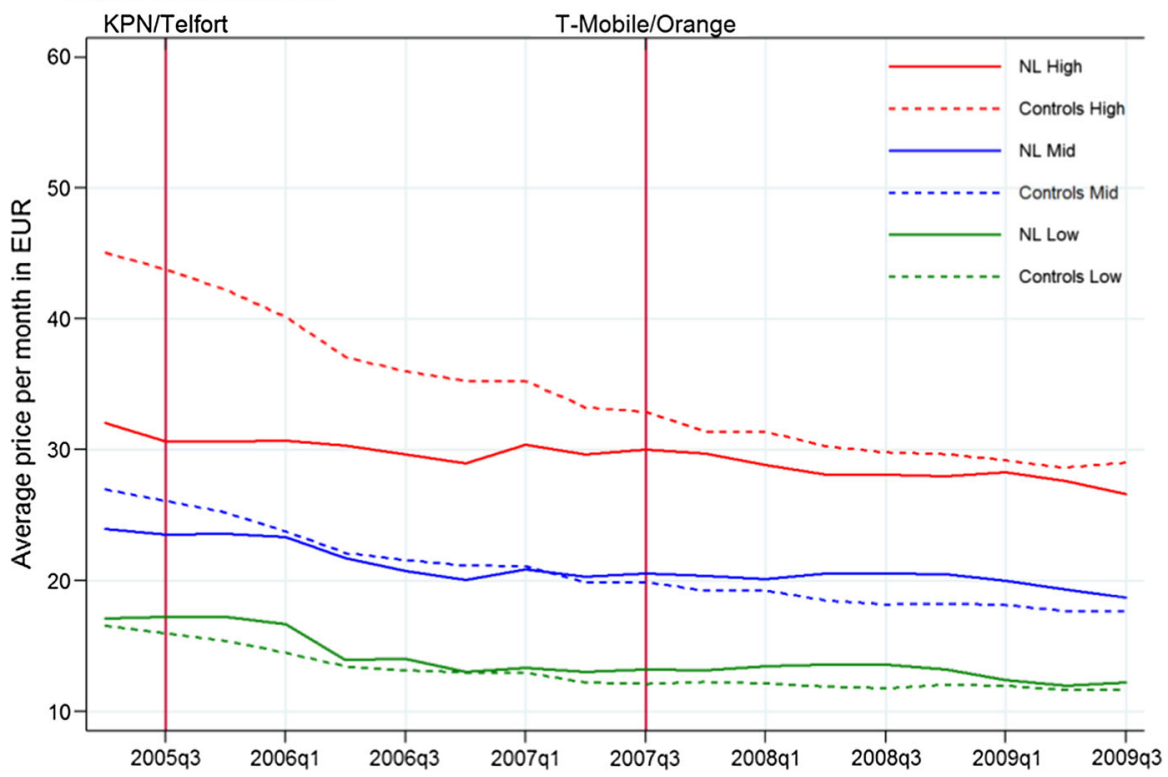

Fig. 2 Price developments in the treated versus the control countries

\subsection{Main Results}

Table 5 presents the results for the Low, Mid basket and High baskets in Austria. In columns 1,3 and 5, the results for the base specification are presented and in columns 2 , 
Table 5 Estimation of merger effect Austria-four cheapest tariffs

\begin{tabular}{lllllll}
\hline $\begin{array}{l}\text { Dep. variable } \\
\text { basket }\end{array}$ & $\begin{array}{l}\text { (1) } \\
\text { Log price } \\
\text { Low }\end{array}$ & $\begin{array}{l}\text { (2) } \\
\text { Log price } \\
\text { Low }\end{array}$ & $\begin{array}{l}\text { (3) } \\
\text { Log price } \\
\text { Mid }\end{array}$ & $\begin{array}{l}\text { Log price } \\
\text { Mid }\end{array}$ & $\begin{array}{l}\text { Log price } \\
\text { High }\end{array}$ & $\begin{array}{l}\text { Log price } \\
\text { High }\end{array}$ \\
\hline Short-term effect & $-0.231^{* * *}$ & -0.019 & $-0.134 * * *$ & -0.056 & -0.074 & $-0.104 *$ \\
& $(0.036)$ & $(0.055)$ & $(0.042)$ & $(0.058)$ & $(0.045)$ & $(0.058)$ \\
Medium-term effect & $-0.340^{* * * *}$ & 0.005 & $-0.180 * *$ & -0.057 & -0.128 & $-0.177 *$ \\
& $(0.052)$ & $(0.096)$ & $(0.071)$ & $(0.102)$ & $(0.074)$ & $(0.095)$ \\
GDP growth & 1.562 & 1.351 & 0.906 & 1.282 & 1.114 & 1.433 \\
& $(1.296)$ & $(1.107)$ & $(1.500)$ & $(1.203)$ & $(1.482)$ & $(1.308)$ \\
Log MTR & 0.007 & 0.128 & 0.098 & 0.120 & 0.130 & 0.125 \\
& $(0.135)$ & $(0.118)$ & $(0.167)$ & $(0.084)$ & $(0.172)$ & $(0.081)$ \\
Observations & 1727 & 1727 & 1727 & 1727 & 1727 & 1727 \\
$\mathrm{R}^{2}$ & 0.737 & 0.754 & 0.815 & 0.841 & 0.832 & 0.865 \\
Country-spec. trend & No & Yes & No & Yes & No & Yes \\
Common trend test $(p$ val $)$ & 0.014 & - & 0.261 & - & 0.674 & - \\
\hline
\end{tabular}

Cluster-robust SE below coefficients (SE clustered at country level)

Time fixed effects and country-MNO fixed-effects

Period: Q2/2004-Q2/2008; 8 quarters pre- and 8 quarters post-merger; Q2/2006 is dropped (merger quarter) Common trend test-null hypothesis of common trend

Significance level: ***1, **5, *10\%

4, and 6 the country-specific specific trend is included. In the Low basket, the common trend test fails.

The T-Mobile/tele.ring merger was modified by commitments. Since our ex-post evaluation does not allow separating the effects of the unmodified merger and of the remedies, the presented results refer to the effects of the merger including the remedies. For all baskets in Austria and both specifications, the results indicate that the merger is associated with a drop in prices compared to the counterfactual of no merger, except for the Low basket specification with the trend included. Moreover, the estimated price reductions seem to grow over time, as the medium-term effects are usually larger (more negative) than the short-term effects. In model (1), we estimate a price reduction of $23 \%$ in the short term and of $34 \%$ in the medium term. Both estimates are statistically significant when we use the cluster robust standard errors with clusters at the country level. However, for this specification we reject the hypothesis that Austria and the control countries share a common pre-merger trend ("common trend test"). In model (2) with the country specific trend, the results become not significant anymore. Looking at Fig. 2, the pre-merger trend in the control group is not continued in the period post-merger. The Mid and High baskets specifications pass the common trend test in the sense that the null-hypothesis of a common trend is not rejected at a 5\% confidence level. For the Mid basket we estimate a price reduction of $13 \%$ in the short term and of $18 \%$ in the medium term (both statistically significant). The estimated price reduction for the High basket is $7 \%$ in the short term and $13 \%$ in the medium term (not statistically significant). For the Mid and High baskets with the country specific trend included, we do observe some differences relative to the estimates without, but 
Table 6 Estimation of merger effect the Netherlands-four cheapest tariffs

\begin{tabular}{|c|c|c|c|c|c|c|}
\hline $\begin{array}{l}\text { Dep. variable } \\
\text { basket }\end{array}$ & $\begin{array}{l}\text { (1) } \\
\text { Log price } \\
\text { Low }\end{array}$ & $\begin{array}{l}(2) \\
\text { Log price } \\
\text { Low }\end{array}$ & $\begin{array}{l}\text { (3) } \\
\text { Log price } \\
\text { Mid }\end{array}$ & $\begin{array}{l}\text { (4) } \\
\text { Log price } \\
\text { Mid }\end{array}$ & $\begin{array}{l}(5) \\
\text { Log price } \\
\text { High }\end{array}$ & $\begin{array}{l}(6) \\
\text { Log price } \\
\text { High }\end{array}$ \\
\hline Short-term effect & $\begin{array}{l}0.062 \\
(0.049)\end{array}$ & $\begin{array}{l}0.148 * * \\
(0.052)\end{array}$ & $\begin{array}{l}0.093 * * \\
(0.035)\end{array}$ & $\begin{array}{l}0.126 * * \\
(0.053)\end{array}$ & $\begin{array}{l}0.133 * * * \\
(0.021)\end{array}$ & $\begin{array}{l}0.050 \\
(0.036)\end{array}$ \\
\hline Medium-term effect & $\begin{array}{l}0.009 \\
(0.050)\end{array}$ & $\begin{array}{l}0.141 * \\
(0.070)\end{array}$ & $\begin{array}{l}0.099 * * \\
(0.042)\end{array}$ & $\begin{array}{l}0.149 \\
(0.084)\end{array}$ & $\begin{array}{l}0.167 * * * \\
(0.036)\end{array}$ & $\begin{array}{l}0.030 \\
(0.063)\end{array}$ \\
\hline GDP growth & $\begin{array}{l}2.598 * * \\
(0.889)\end{array}$ & $\begin{array}{l}1.315 * * \\
(0.581)\end{array}$ & $\begin{array}{l}1.964 * * \\
(0.765)\end{array}$ & $\begin{array}{l}0.980^{*} \\
(0.456)\end{array}$ & $\begin{array}{l}1.825 * * \\
(0.644)\end{array}$ & $\begin{array}{l}0.806^{*} \\
(0.384)\end{array}$ \\
\hline Log MTR & $\begin{array}{l}0.015 \\
(0.126)\end{array}$ & $\begin{array}{l}-0.032 \\
(0.065)\end{array}$ & $\begin{array}{l}-0.032 \\
(0.088)\end{array}$ & $\begin{array}{l}-0.036 \\
(0.037)\end{array}$ & $\begin{array}{l}-0.083 \\
(0.065)\end{array}$ & $\begin{array}{l}-0.029 \\
(0.059)\end{array}$ \\
\hline Observations & 1318 & 1318 & 1318 & 1318 & 1318 & 1318 \\
\hline $\mathrm{R}^{2}$ & 0.707 & 0.727 & 0.785 & 0.806 & 0.825 & 0.842 \\
\hline Country-spec. trend & No & Yes & No & Yes & No & Yes \\
\hline Common trend test ( $p$ val) & 0.039 & - & 0.410 & - & 0.005 & - \\
\hline
\end{tabular}

Cluster-robust SE below coefficients (SE clustered at country level)

Time fixed effects and country-MNO fixed-effects

Period: Q2/2005-Q3/2009; 4 quarters pre- and 8 quarters post-merger; Q2-Q3/2007 excluded quarters (merger quarters)

Common trend test - null hypothesis of common trend

Significance level: $* * * 1, * * 5, * 10 \%$

in both cases the estimated effects remain negative. For the High basket, the effects become significant. Overall these results indicate that the price development in Austria post-merger is not associated with relative price increases.

Finally both the coefficients associated to MTR and GDP are always positive, suggesting (as expected) a positive relation between mobile prices and each of these measures, however, the effects are not statistically significant.

Table 6 presents the results of our model corresponding to Eq. (1), for the Low, Mid and High baskets in the Netherlands. In columns 1, 3 and 5, the results of the base specification are presented and in columns 2,4 , and 6 the country specific trend is included.

Looking at the results in Table 6, in all specifications the Dutch merger is associated with an increase in prices. The increase in price is positive but not significant for the Low basket in column (1), and increases and becomes significant when the trend is included, see column (2). The price increase for the Mid basket is around 9\% or more. For the High basket the price increase attains $13-17 \%$ for the base specification but the increase becomes insignificant when the trend is included.

As mentioned above, the KPN/Telfort merger may have resulted in price changes especially in the two years after that merger. To the extent the prices were increasing from Q2/2006 to Q1/2007 due to the KPN/Telfort merger, the estimated effect of the T-Mobile/Orange merger may be biased upwards for the base specification. Based on Fig. 2 as regards the Low and Mid baskets, the prices in the Netherlands did not markedly increase during Q2/2006 to Q1/2007 relative to the control countries, which 
Table 7 Estimation of merger effect Austria-four cheapest tariffs, pre-paid only

\begin{tabular}{|c|c|c|c|c|c|c|}
\hline $\begin{array}{l}\text { Dep. variable } \\
\text { basket }\end{array}$ & $\begin{array}{l}(1) \\
\text { Log price } \\
\text { Low }\end{array}$ & $\begin{array}{l}(2) \\
\text { Log price } \\
\text { Low }\end{array}$ & $\begin{array}{l}(3) \\
\text { Log price } \\
\text { Mid }\end{array}$ & $\begin{array}{l}\text { (4) } \\
\text { Log price } \\
\text { Mid }\end{array}$ & $\begin{array}{l}(5) \\
\text { Log price } \\
\text { High }\end{array}$ & $\begin{array}{l}(6) \\
\text { Log price } \\
\text { High }\end{array}$ \\
\hline Short-term effect & $\begin{array}{l}-0.380 * * * \\
(0.054)\end{array}$ & $\begin{array}{l}-0.116^{*} \\
(0.061)\end{array}$ & $\begin{array}{l}-0.357 * * * \\
(0.082)\end{array}$ & $\begin{array}{l}-0.069 \\
(0.082)\end{array}$ & $\begin{array}{l}-0.348 * * * \\
(0.086)\end{array}$ & $\begin{array}{l}-0.061 \\
(0.087)\end{array}$ \\
\hline Medium-term effect & $\begin{array}{l}-0.502^{* * *} \\
(0.085)\end{array}$ & $\begin{array}{l}-0.075 \\
(0.107)\end{array}$ & $\begin{array}{l}-0.445^{* * *} \\
(0.132)\end{array}$ & $\begin{array}{l}0.018 \\
(0.143)\end{array}$ & $\begin{array}{l}-0.426 * * \\
(0.144)\end{array}$ & $\begin{array}{l}0.037 \\
(0.155)\end{array}$ \\
\hline GDP growth & $\begin{array}{l}0.313 \\
(0.824)\end{array}$ & $\begin{array}{l}1.596 \\
(1.086)\end{array}$ & $\begin{array}{l}-0.150 \\
(1.189)\end{array}$ & $\begin{array}{l}1.926 \\
(1.191)\end{array}$ & $\begin{array}{l}-0.568 \\
(1.411)\end{array}$ & $\begin{array}{l}2.296 \\
(1.291)\end{array}$ \\
\hline Log MTR & $\begin{array}{l}-0.096 \\
(0.241)\end{array}$ & $\begin{array}{l}0.082 \\
(0.175)\end{array}$ & $\begin{array}{l}-0.049 \\
(0.358)\end{array}$ & $\begin{array}{l}0.157 \\
(0.200)\end{array}$ & $\begin{array}{l}0.020 \\
(0.371)\end{array}$ & $\begin{array}{l}0.198 \\
(0.188)\end{array}$ \\
\hline Observations & 1148 & 1148 & 1148 & 1148 & 1148 & 1148 \\
\hline $\mathrm{R}^{2}$ & 0.756 & 0.781 & 0.722 & 0.767 & 0.712 & 0.762 \\
\hline Country-spec. Trend & No & Yes & No & Yes & No & Yes \\
\hline Common trend test ( $p$ val) & 0.000 & & 0.000 & & 0.000 & \\
\hline
\end{tabular}

Cluster-robust SE below coefficients (SE clustered at country level)

Time fixed effects and country-MNO fixed-effects

Period: Q2/2004-Q2/2008; 8 quarters pre- and 8 quarters post-merger; Q2/2006 is dropped (merger quarter) Common trend test-null hypothesis of common trend

Significance level: ***1\%,**5\%,*10\%

indicates the absence of significant (persistent) late effects of the KPN/Telfort merger. However, as regards the High basket, the prices in the Netherlands increased during Q2/2006 to Q1/2007 relative to the control countries. For this reason there is some risk, especially for the High basket, that some of the estimated price increase may not be causally linked to the T-Mobile/Orange merger. Formally, the common trend test for the Low and High baskets is not passed which may reflect medium-term effects of the earlier KPN/Telfort merger. In any event, the reliability of the trend specification applied to the Dutch case may suffer from the very short pre-merger period (4 quarters) and the effects of the KPN/Telfort merger. ${ }^{19}$

We observe that the time varying control variables (MTRs and GDP) in some cases do not fully explain the observed differences in the pre-merger price trends across countries. This is also reflected in our test for a common trend which in some instances indicates diverging trends pre-merger.

\subsection{Robustness Tests}

Our first robustness test excludes all post-paid tariffs and runs the analysis only on the pre-paid tariffs. As pre-paid tariff plans usually do not include a valuable subsidized handset, this somewhat addresses the issue of handset subsidies, which are not recorded

19 We cannot exclude that in the absence of the KPN/Telfort merger there would have been a steeper price decrease in Q2/2006 to Q1/2007, which would have likely implied higher estimated price effects of the T-Mobile/Orange merger in the specification with country specific trends. 
Table 8 Estimation of merger effect the Netherlands-four cheapest tariffs, pre-paid only

\begin{tabular}{|c|c|c|c|c|c|c|}
\hline $\begin{array}{l}\text { Dep. variable } \\
\text { basket }\end{array}$ & $\begin{array}{l}\text { (1) } \\
\text { Log price } \\
\text { Low }\end{array}$ & $\begin{array}{l}(2) \\
\text { Log price } \\
\text { Low }\end{array}$ & $\begin{array}{l}\text { (3) } \\
\text { Log price } \\
\text { Mid }\end{array}$ & $\begin{array}{l}\text { (4) } \\
\text { Log price } \\
\text { Mid }\end{array}$ & $\begin{array}{l}(5) \\
\text { Log price } \\
\text { High }\end{array}$ & $\begin{array}{l}(6) \\
\text { Log price } \\
\text { High }\end{array}$ \\
\hline Short-term effect & $\begin{array}{l}0.094^{*} \\
(0.045)\end{array}$ & $\begin{array}{l}0.155 \\
(0.093)\end{array}$ & $\begin{array}{l}0.131^{* * *} \\
(0.041)\end{array}$ & $\begin{array}{l}0.128 \\
(0.082)\end{array}$ & $\begin{array}{l}0.150^{* * *} \\
(0.047)\end{array}$ & $\begin{array}{l}0.096 \\
(0.062)\end{array}$ \\
\hline Medium-term effect & $\begin{array}{l}0.077 \\
(0.083)\end{array}$ & $\begin{array}{l}0.183 \\
(0.162)\end{array}$ & $\begin{array}{l}0.149 * \\
(0.081)\end{array}$ & $\begin{array}{l}0.152 \\
(0.155)\end{array}$ & $\begin{array}{l}0.188^{*} \\
(0.090)\end{array}$ & $\begin{array}{l}0.107 \\
(0.124)\end{array}$ \\
\hline GDP growth & $\begin{array}{l}3.945^{* * *} \\
(1.055)\end{array}$ & $\begin{array}{l}1.364 \\
(0.905)\end{array}$ & $\begin{array}{l}3.547^{* * *} \\
(1.159)\end{array}$ & $\begin{array}{l}0.925 \\
(0.870)\end{array}$ & $\begin{array}{l}3.316^{* *} \\
(1.398)\end{array}$ & $\begin{array}{l}0.937 \\
(0.791)\end{array}$ \\
\hline Log MTR & $\begin{array}{l}0.061 \\
(0.170)\end{array}$ & $\begin{array}{l}0.032 \\
(0.226)\end{array}$ & $\begin{array}{l}0.015 \\
(0.133)\end{array}$ & $\begin{array}{l}0.076 \\
(0.138)\end{array}$ & $\begin{array}{l}-0.026 \\
(0.129)\end{array}$ & $\begin{array}{l}0.049 \\
(0.069)\end{array}$ \\
\hline Observations & 897 & 897 & 897 & 897 & 897 & 897 \\
\hline $\mathrm{R}^{2}$ & 0.676 & 0.717 & 0.714 & 0.753 & 0.730 & 0.772 \\
\hline Country-spec. Trend & No & Yes & No & Yes & No & Yes \\
\hline Common trend test ( $p$ val) & 0.370 & - & 0.888 & - & 0.276 & - \\
\hline
\end{tabular}

Cluster-robust SE below coefficients (SE clustered at country level)

Time fixed effects and country-MNO fixed-effects

Period: Q2/2005-Q3/2009; 4 quarters pre- and 8 quarters post-merger; Q2-Q3/2007 excluded quarters (merger quarters)

Common trend test-null hypothesis of common trend

Significance level: ***1\%,**5\%,*10\%

separately in any of the datasets we have and therefore may bias our results. ${ }^{20}$ In Table 7, the results for Austria are presented. For all baskets, the common trend test is failed. In the specification without the country specific trend, we estimate even stronger price reductions for all baskets, ranging from a 35 to $50 \%$ price decrease than in our base model. In this specification, also the effects for the High basket are significant. However, if the common trend is included, the price decreases become much smaller and even positive for the medium-term for the Mid and High basket. Most coefficients are however not significant.

For the Netherlands, the common trend test is passed for all three baskets (see Table 8). The effects are in line with main analysis indicating a price increase of 9$19 \%$. Also the short-term effect for the Low basket becomes significant at the $10 \%$ level. If the country specific trend is included, the price effects have more or less the same magnitude, but are not significant.

As a further robustness check, we estimate our price measure only on the basis of the two cheapest tariffs. Also in the specification without the country specific trend, we obtain results that are largely comparable to the main estimates. In Austria, the effects for the High basket become significant at the $10 \%$ level (see Table 9). Overall, under the assumption that absent the merger the price trend in Austria would have followed the trend of the control countries (after accounting for MTRs and GDP-growth), the results

\footnotetext{
20 For instance if handset subsidies changed in Austria or the Netherlands as a result of the merger but not in the control group countries.
} 
Table 9 Estimation of merger effect Austria-two cheapest tariffs

\begin{tabular}{lllllll}
\hline $\begin{array}{l}\text { Dep. variable } \\
\text { basket }\end{array}$ & $\begin{array}{l}(1) \\
\text { Log price } \\
\text { Low }\end{array}$ & $\begin{array}{l}(2) \\
\text { Log price } \\
\text { Low }\end{array}$ & $\begin{array}{l}(3) \\
\text { Log price } \\
\text { Mid }\end{array}$ & $\begin{array}{l}\text { Log price } \\
\text { Mid }\end{array}$ & $\begin{array}{l}\text { Log price } \\
\text { High }\end{array}$ & $\begin{array}{l}\text { Log price } \\
\text { High }\end{array}$ \\
\hline Short-term effect & $-0.302^{* * *}$ & 0.006 & $-0.124^{* *}$ & 0.014 & $-0.104^{* *}$ & -0.112 \\
& $(0.033)$ & $(0.056)$ & $(0.040)$ & $(0.07)$ & $(0.042)$ & $(0.07)$ \\
Medium-term effect & $-0.358^{* * *}$ & 0.149 & -0.134 & 0.091 & $-0.146^{*}$ & -0.159 \\
& $(0.057)$ & $(0.1)$ & $(0.077)$ & $(0.124)$ & $(0.075)$ & $(0.116)$ \\
GDP growth & 0.652 & 1.321 & -0.344 & 1.010 & 0.265 & 1.039 \\
Log MTR & $(1.238)$ & $(1.135)$ & $(1.483)$ & $(1.230)$ & $(1.447)$ & $(1.292)$ \\
& -0.020 & 0.177 & 0.107 & 0.151 & 0.159 & $0.145^{*}$ \\
Observations & $(0.144)$ & $(0.139)$ & $(0.169)$ & $(0.099)$ & $(0.164)$ & $(0.073)$ \\
$\mathrm{R}^{2}$ & 864 & 864 & 864 & 864 & 864 & 864 \\
Country-spec. trend & 0.814 & 0.833 & 0.862 & 0.890 & 0.874 & 0.904 \\
Common trend test $(p$ val $)$ & 0.001 & Yes & No & Yes & No & Yes \\
\hline
\end{tabular}

Cluster-robust SE below coefficients (SE clustered at country level)

Time fixed effects and country-MNO fixed-effects

Period: Q2/2004-Q2/2008; 8 quarters pre- and 8 quarters post-merger; Q2/2006 is dropped (merger quarter)

Common trend test-null hypothesis of common trend

Significance level: ***1\%,**5\%,*10\%

suggest relatively strong price reductions associated with the merger with estimates of price reductions ranging from 10 to $35 \%$.

However, the trend test is not passed for the Low and Mid basket. If we include the country-specific trends, the effects for the Low and Mid basket become positive, although not significant.

For the Netherlands, the results are presented in Table 10. In contrast to the main specification, the common trend test is passed for all baskets in the Netherlands. The estimated effect is similar to that of the main specification for the Low basket. The effects are slightly stronger with significant price increases of $12-18 \%$ for the Mid and High basket. If the trend is included, the effects remain positive but are significant less often. Overall, there are indications that a price increase is associated with the T-Mobile/Orange merger (relative to the scenario absent the merger).

\section{Discussion and Conclusion}

In Austria, for (almost) all specifications we estimate negative price effects associated with the remedied merger. The estimates that we consider more reliable range from $-2 \%$ up to $-20 \%$, both in the short term and in the medium term. In light of these results it appears very unlikely that the merger resulted in (significant) price increase relative to the scenario in the absence of the merger. Importantly, we can only estimate the effects of the mergers as modified by commitments. In Austria, the structural commitments offered by the merging parties are likely to have strengthened the smallest 
Table 10 Estimation of merger effect Netherlands-two cheapest tariffs

\begin{tabular}{|c|c|c|c|c|c|c|}
\hline $\begin{array}{l}\text { Dep. variable } \\
\text { basket }\end{array}$ & $\begin{array}{l}\text { (1) } \\
\text { Log price } \\
\text { Low }\end{array}$ & $\begin{array}{l}(2) \\
\text { Log price } \\
\text { Low }\end{array}$ & $\begin{array}{l}\text { (3) } \\
\text { Log price } \\
\text { Mid }\end{array}$ & $\begin{array}{l}\text { (4) } \\
\text { Log price } \\
\text { Mid }\end{array}$ & $\begin{array}{l}(5) \\
\text { Log price } \\
\text { High }\end{array}$ & $\begin{array}{l}(6) \\
\text { Log price } \\
\text { High }\end{array}$ \\
\hline Short-term effect & $\begin{array}{l}0.073 \\
(0.054)\end{array}$ & $\begin{array}{l}0.151^{*} \\
(0.078)\end{array}$ & $\begin{array}{l}0.118^{* *} \\
(0.042)\end{array}$ & $\begin{array}{l}0.118 \\
(0.086)\end{array}$ & $\begin{array}{l}0.125^{* * *} \\
(0.027)\end{array}$ & $\begin{array}{l}0.099^{* *} \\
(0.044)\end{array}$ \\
\hline Medium-term effect & $\begin{array}{l}0.027 \\
(0.075)\end{array}$ & $\begin{array}{l}0.151 \\
(0.121)\end{array}$ & $\begin{array}{l}0.134^{*} \\
(0.064)\end{array}$ & $\begin{array}{l}0.131 \\
(0.142)\end{array}$ & $\begin{array}{l}0.182^{* * *} \\
(0.058)\end{array}$ & $\begin{array}{l}0.138 \\
(0.083)\end{array}$ \\
\hline GDP growth & $\begin{array}{l}2.296^{* *} \\
(0.967)\end{array}$ & $\begin{array}{l}0.834 \\
(0.485)\end{array}$ & $\begin{array}{l}1.677^{*} \\
(0.923)\end{array}$ & $\begin{array}{l}0.837 \\
(0.506)\end{array}$ & $\begin{array}{l}1.459 \\
(0.885)\end{array}$ & $\begin{array}{l}0.546 \\
(0.560)\end{array}$ \\
\hline Log MTR & $\begin{array}{l}0.037 \\
(0.140)\end{array}$ & $\begin{array}{l}0.051 \\
(0.086)\end{array}$ & $\begin{array}{l}-0.03 \\
(0.102)\end{array}$ & $\begin{array}{l}-0.001 \\
(0.051)\end{array}$ & $\begin{array}{l}-0.083 \\
(0.091)\end{array}$ & $\begin{array}{l}-0.022 \\
(0.068)\end{array}$ \\
\hline Observations & 660 & 660 & 660 & 660 & 660 & 660 \\
\hline $\mathrm{R}^{2}$ & 0.817 & 0.861 & 0.852 & 0.896 & 0.864 & 0.900 \\
\hline Country-spec. trend & No & Yes & No & Yes & No & Yes \\
\hline Common trend test ( $p$ val) & 0.174 & - & 0.929 & - & 0.416 & - \\
\hline
\end{tabular}

Cluster-robust SE below coefficients (SE clustered at country level)

Time fixed effects and country-MNO fixed-effects

Period: Q2/2005-Q3/2009; 4 quarters pre- and 8 quarters post-merger; Q2-Q3/2007 excluded quarters (merger quarters)

Common trend test-null hypothesis of common trend

Significance level: $* * * 1, * * 5, * 10 \%$

two operators (Orange and especially Hutchinson), as market developments after the merger appear to show.

Whilst after the T-Mobile/Orange merger prices in Netherlands did not increase in absolute terms, the prices increased relative to the estimated prices in the absence of the merger. The price increases appear to be more pronounced for heavier users of mobile services, with estimated price increases in the range between 10 and 15\%. However, it is difficult to attribute these price increases firmly to the T-Mobile/Orange merger in light of possible confounding effects of the earlier KPN/Telfort merger as well as further specificities of the Dutch analysis. Nevertheless, the T-Mobile/Orange merger, possibly together with the KPN/Telfort merger, may have led to price increases. In light of these results, it would be interesting to revisit the argument whether a vibrant MVNO segment pre-merger can be expected to impose a sufficient competitive constraint postmerger. This could be for example done by studying how wholesale terms developed compared to the retail terms.

These results suggest that merger effects of mobile telecom mergers appear to be driven by characteristics of the respective markets and the merging parties (such as the degree of competitive interaction between the merging MNOs) as well as by commitments that were offered to obtain competition clearance. Indeed, the two analysed mergers differed significantly. For example, at the time the Austrian merger was announced, there were five competing MNOs whereas in the Netherlands there were only four competing MNOs pre-merger. Moreover, the price decreases observed in 
Austria may reflect that competing MNOs were strengthened by means of the imposed remedies.

The relatively low precision of the estimated price effects is not surprising, as we have a relatively small sample of control countries that we compare to only a single affected country. Hence, we are not able to separate the merger effects from idiosyncratic post-merger price dynamics in Austria or the Netherlands, respectively, and we cannot exclude that idiosyncratic price developments in some of the control countries are affecting the results. In this respect, in the Netherlands, the presence of a relatively large MVNO segment might result in somewhat different competition dynamics than in other countries where there is no sizable MVNO segment. More generally, prices in all countries appear to be substantially affected over time by idiosyncratic effects.

One important consideration for the interpretation of ex-post evaluations of mergers is the role of merger control. As illustrated by the analysis of the Austrian T-Mobile/tele.ring merger, often only the effect of the merger as modified by commitments can be estimated and the necessity of the commitments cannot be studied. ${ }^{21}$ However, if a remedied merger still entails significant anti-competitive effects, this indicates that the remedies were insufficient from an ex-post perspective.

As regards evaluation of mobile telecom mergers we see in particular two avenues for future research. First, it would be important to study also implications of mobile telecom mergers on mobile network quality. If sufficient data on network quality are available, similar techniques could be applied to study the effect of mergers on network quality. However, as mobile telecom investments usually require a lead time of several years, the analysed period probably needs to be extended, which in turn may exacerbate the above-mentioned issues of dealing with idiosyncratic effects. Second, as the number of mobile mergers increases over time, additional insights can be gained from broad econometric studies on the determinants of mobile telecom merger effects, such as Genakos et al. (2015).

Acknowledgements We are very grateful for the feedback received from the editor and two anonymous referees. Eugenio Miravete and Matthew Weinberg provided useful comments on an earlier version of this study that we sincerely appreciated. We thank Georg Ecker, Gabor Koltay and Robert Stil for important contributions to the project and Francesco Decarolis for several very helpful discussions and comments. Otto Toivanen, Tommaso Valletti, Frank Verboven and Christine Zulehner also provided valuable comments and suggestions. We are also grateful for the support and suggestions provided by many colleagues from the Austrian Regulatory Authority for Broadcasting and Telecommunications, The Netherlands Authority for Consumers and Markets, and DG COMP.

Open Access This article is distributed under the terms of the Creative Commons Attribution 4.0 International License (http://creativecommons.org/licenses/by/4.0/), which permits unrestricted use, distribution, and reproduction in any medium, provided you give appropriate credit to the original author(s) and the source, provide a link to the Creative Commons license, and indicate if changes were made.

\footnotetext{
21 Specifically, commitments will be likely imposed whenever the involved competition authority expects that the unmodified merger would cause significant anti-competitive effects. Therefore, if no significant anti-competitive effects are found for a merger which was conditionally cleared, this indicates that the remedies were sufficient for that case. Still, on this basis, it could not be concluded that the merger would have had no significant anti-competitive effects even if no commitments had been imposed.
} 


\section{References}

Aguzzoni L., Argentesi E., Buccirossi P., Ciari L., Duso T., Tognoni M. et al. (2011). The ex-post evaluation of two merger decisions. A Report prepared by Lear for the UK Competition Commission, CC1057.

Angrist, J., \& Pischke, J. (2008). Mostly harmless econometrics: An empiricist's companion (eBook ed.). Princeton: Princeton University Press.

Ashenfelter, O. (1978). Estimating the effect of training programs on earnings. Review of Economics and Statistics, 60, 47-57.

Ashenfelter, O., \& Card, D. (1985). Using the longitudinal structure of earnings to estimate the effect of training programs. Review of Economics and Statistics, 67, 648-660.

Ashenfelter O., \& Hosken D. (2008). The effect of mergers on consumer prices: Evidence from five selected case studies. NBER Working Paper, W13859.

Ashenfelter, O., Hosken, D., \& Weinberg, M. (2013). The price effects of a large merger of manufacturers: A case study of Maytag-Whirlpool. American Economic Journal: Economic Policy, 5(1), 239-61.

Bertrand, M., Duflo, E., \& Mullainathan, S. (2004). How much should we trust in Differences-in-Differences Estimates? The Quarterly Journal of Economics, 119(1), 249-275.

Brewer M., Crossley T., \& Joyce R. (2013). Inference with difference-in-differences revisited. Working paper. Available at http://ssrn.com/abstract=2363229.

Cameron, C., Gelbach, B., \& Miller, D. L. (2008). Bootstrap-based improvements for inference with clustered errors. The Review of Economics and Statistics, 90(3), 414-427.

Choné, P., \& Linnemer, L. (2012). A treatment effect method for merger analysis with an application to parking prices in Paris. Journal of Industrial Economics, 60, 631-656.

Csorba G., \& Pápai Z. (2015). Does one more or one less mobile operator affect prices? A comprehensive ex-post evaluation of entries and mergers in European mobile telecommunication markets. Discussion paper. Available at http://econ.core.hu/file/download/mtdp/MTDP1541.pdf.

Farrell, J., \& Shapiro, C. (2010). Antitrust evaluation of horizontal mergers: An economic alternative to market definition. The B.E. Journal of Theoretical Economics, 10(1), 1-39.

Focarelli, D., \& Panetta, F. (2003). Are mergers beneficial to consumers? Evidence from the market for bank deposits. American Economic Review, 93(4), 1152-1172.

Frontier Economics. (2015). Assessing the case for in-country mobile consolidation. Report. Available at http://www.gsma.com/publicpolicy/wp-content/uploads/2015/05/Assessing_the_case_for_ in-country_mobile_consolidation.pdf.

Genakos C., Valletti T., \& Verboven F. (2015). Evaluating market consolidation in mobile communications. Cerre Report. Available at: http://cerre.eu/sites/cerre/files/150915_CERRE_Mobile_Consolidation_ Report_Final.pdf.

Imbens, G. M., \& Wooldridge, J. M. (2009). Recent developments in the econometrics of program evaluation. Journal of Economic Literature, 47, 5-86.

Ivaldi M., Jullien B., Rey P., Seabright P., \& Tirole J. (2003). The economics of unilateral effects. Report for DG Competition, European Commission. Available at http://idei.fr/doc/wp/2003/economics_ unilaterals.pdf.

Kwoka, J. (2013). Does merger control work? A retrospective on U.S. enforcement actions and merger outcomes. Antitrust Law Journal, 78, 619-640.

MacKinnon J. G., \& Webb M. D. (2014). Wild bootstrap inference for wildly different cluster sizes (No. 1314). Queen's Economics Department Working Paper.

Mariuzzo, F., Ormosi, P. L., \& Havell, R. (2016). What can merger retrospectives tell us? An assessment of European mergers. CCP Working Paper 16-4. Available at https://papers.ssrn.com/sol3/papers.cfm? abstract_id=2781509.

Nitsche R., \& Affeldt P. (2014). A price concentration study on European mobile telecom markets. ESMT Working Paper No. WP-14-07.

O’Neill, S., Kreif, N., Grieve, R., Sutton, M., \& Sekhon, J. S. (2016). Estimating causal effects: Considering three alternatives to difference-in-differences estimation. Health Service Outcomes Research Methods, $16,1-21$.

OECD. (2006). OECD Price Benchmarking Baskets 2006. Available at http://www.oecd.org/internet/ broadband/41049579.pdf. 
Wolfers, J. (2006). Did unilateral divorce laws raise divorce rates? A reconciliation and new results. American Economic Review, 96(5), 1802-1820.

Wooldridge, J. M. (2003). Cluster-sample methods in applied econometrics. American Economic Review, 93(2), 133-138. 